\title{
DESAFÍOS EN LA CONSTRUCCION DE PROCEDIMIENTOS DE AUTORREGULACION EN LOS COLECTIVOS AUTOGESTIVOS DE TRABAJADORES: EXPERIENCIAS Y REFLEXIONES SOBRE FÁBRICAS Y EMPRESAS RECUPERADAS EN ARGENTINA ${ }^{1}$
}

\author{
Cecilia Calloway ${ }^{2}$ \\ Bruno Colombari ${ }^{3}$ \\ Santiago Iorio 4
}

Las experiencias de fábricas y empresas recuperadas (FER) durante los comienzos de la década del ${ }^{\prime} 90^{5}$ se dieron en una coyuntura signada por la profundización de medidas neoliberales cuyo resultado, entre otros, fue el avance de las privatizaciones y la desindustrialización (Cenda, 2010). En este contexto, los procesos de recuperación de las unidades productivas se constituyeron como experiencias novedosas que ponían en tensión las significaciones sobre la propiedad privada y el derecho al trabajo.

Este proceso eclosiona y toma una mayor visibilidad en el marco de los estallidos sociales de diciembre de 2001. Desde dicho año hasta 2003 se registra la mayor cantidad de recuperaciones y conflictos ligados a ellas ${ }^{6}$. La recuperación de empresas o fábricas quebradas se presenta como una alternativa para mantener la fuente laboral entre el conjunto de los trabajadores que se ven desempleados. El proceso que se da tras la quiebra y el abandono de la fábrica por parte del patrón, es la ocupación de la misma por parte de los trabajadores y posteriormente la organización autogestiva para comenzar con la producción.

Se trabajará sobre una hipótesis ya planteada en Política y Subjetividad: asambleas barriales y fábricas recuperadas (Fernández, 2006, Fajn, 2003; Rebón, Salgado 2009) y sostenida también en Fábricas y Empresas Recuperadas: Protesta social, Autogestión y Rupturas en la Subjetividad (Fajn, 2003), allí se afirma que el nivel de conflictividad por el que tuvieron que atravesar estas FER repercute

\footnotetext{
${ }^{1}$ Este escrito se enmarca en el trabajo de investigación realizado desde Observatorio Social de Empresas Recuperadas y Autogestionadas (OSERA) y particularmente en el proyecto de investigación "Los procedimientos de autorregulación y su relación con la producción socio-histórica de subjetividad" inscripto en el Departamento de Estudios Sociológicos del Centro Cultural Cooperación.

${ }^{2}$ Universidad de Buenos Aires, Argentina.

${ }^{3}$ Universidad de Buenos Aires, Argentina.

${ }^{4}$ Universidad de Buenos Aires, Argentina.

${ }^{5}$ Un ejemplo de esto es el proceso de recuperación de empresas impulsada por la seccional Quilmes de la UOM.
} 
directamente en la posibilidad de darse a sí mismos, como colectivo de trabajadores, una modalidad horizontal y autogestiva muy distante a la verticalidad vivida a diario en una fábrica con patrón. En este sentido, se podría decir que cuanto mayor sea el conflicto atravesado en la toma y ocupación de la fábrica o empresa, mayor es la distancia con una modalidad de organización anterior (vertical y delegativa), produciéndose una diversidad tal de poder alcanzar mayores grados de autogestión. Así mismo, consideramos la autorregulación como:

Un conjunto de prácticas colectivas que reemplazan en una organización autogestiva a la disciplina fabril propia de la organizacional vertical. La autorregulación se pone en marcha en lo cotidiano y presupone la invención de una respuesta ante los problemas diarios que obstaculizan la producción (Calloway, 2010).

La autorregulación conforma una de las aristas de la autogestión. Ciertos colectivos que han logrado conquistar una mayor autogestión, es decir, un mayor nivel de participación del conjunto de los trabajadores en aquellos espacios que no implican el puesto específico de trabajo y un mayor grado de horizontalidad con respecto a la toma de decisiones, logran a su vez construir procedimientos de autorregulación más lejanos a la disciplina fabril tradicional resignificando viejas prácticas e inventando procedimientos para esta "nueva disciplina". Esto permite pensar que a mayores grados de autogestión conquistados por los colectivos de trabajadores, mayor será también el cambio en sus posicionamientos subjetivos y la tensión ${ }^{7}$ que puedan sostener entre los modos socio históricos de subjetivación tradicionales y la producción de subjetividad.

Consideramos que el año 2003 marca, en cuanto a las estadísticas ${ }^{8}$, un cambio en el panorama social de las FER. Hasta 2003 estas se encontraban en un contexto hostil de lucha que ni las amparaba ni las legitimaba en sus reclamos. A partir del nuevo panorama político y económico, se pusieron en marcha desde el Estado determinados programas y proyectos que permitieron otorgar respuestas parciales a algunas necesidades del sector. Así también comenzó un lento camino de legitimación de dicho

\footnotetext{
${ }^{7}$ “Con tensión se quiere significar la presencia de criterios antagónicos que coexisten en distintas situaciones asamblearias y donde la propia dinámica de estos colectivos lleva a que no se llegue a optar por una de las posiciones sino que coexistan en diferente grado de dificultad, enfrentamiento, oposición, consenso, disenso. Son tensiones que operan algunas veces de forma explícita, otras de forma implícita, pero que siempre presentan la particularidad de insistir". En Política y subjetividad: asambleas barriales y fábricas recuperadas". (Fernández, Borakievich, Rivera, 2006:75).

${ }^{8}$ El $85 \%$ de las empresas relevadas en el 2010, manifestó haber recibido algún tipo de subsidio por parte del Estado, esto se contrapone con un 45\% de empresas que en el año 2004 habían manifestado haber recibido algún subsidio (Ruggeri, 2010).
} 
proceso que tuvo su culminación con la modificación a la ley de quiebras, transformando algo que se constituía como legítimo en legal. Una conquista importante pero no suficiente en los reclamos de estos trabajadores.

Desde allí podríamos pensar qué sucede con las FER después de 2003, siendo que el contexto social cambió en muchos aspectos. Algunos trabajos también plantean que los niveles de conflictividad durante la toma no han sido tan altos como en épocas anteriores $^{9}$. Por esto, creemos que resulta relevante analizar el modo en que se configuraron los campos de lucha en los dos períodos mencionados donde los diversos actores económicos y políticos fueron re-definiendo con el tiempo sus estrategias e intereses delimitando nuevos escenarios de recuperación. Consideramos que en estos contextos se reconfiguraron los diferentes mecanismos de legitimación política de estas experiencias en relación a la intervención estatal en materia técnico/económico y jurídica/legal (Hudson, 2011).

Consideramos que estas transformaciones en los imaginarios sociales constituyen un proceso que produce una nueva modalidad en la conformación de los colectivos de trabajadores autogestivos, en los procedimientos de autorregulación y la producción de subjetividad.

Este trabajo se basa en los resultados de la investigación cualitativa iniciada a finales de 2011 tanto en el ámbito de la ciudad como en la provincia de Buenos Aires. Las técnicas de recolección de información utilizada fueron la entrevista semi estructurada y la observación tanto participante como no participante. Las reflexiones del presente artículo se sitúan a partir del trabajo de campo realizado en cuatro empresas de diferente rubro (industria de la madera, industria metalúrgica, industria gráfica e industria textil) y recuperadas en distintos años que implican diferentes escenarios económicos y políticos ${ }^{10}$.

\section{El contexto social durante los '90 hasta 2003}

El despliegue de la lógica neoliberal iniciada a partir de la dictadura militar de 1976 y profundizada por los sucesivos gobiernos hasta el 2003 se tradujo en un proceso

\footnotetext{
9 “Como podemos ver, el nivel mayor [de represión] se dio entre los años 2002 y 2004, donde el $60 \%$ de las ERT ocupadas fue objeto de alguna medida represiva. A partir de allí, este número bajó al $40 \%$ y en los últimos tres años [2008-2009-2010] se redujo algo más" (Ruggeri, 2010:27).

${ }^{10} \mathrm{El} \mathrm{nombre} \mathrm{de} \mathrm{las} \mathrm{personas} \mathrm{entrevistadas} \mathrm{fue} \mathrm{modificado} \mathrm{con} \mathrm{la} \mathrm{intención} \mathrm{de} \mathrm{preservar} \mathrm{su} \mathrm{identidad.}$
} 
de fragmentación del tejido social que consolidó una dinámica descolectivizadora ${ }^{11}$ en la sociedad. Este proceso fue redefiniendo el campo de organización y lucha de los sectores trabajadores ante las políticas de Estado que profundizaron el avance del desempleo y la precarización laboral. Al quedar relegada la producción industrial, el protagonismo de los repertorios clásicos de protestas laborales, ligados al sindicalismo tradicional, disminuyó sensiblemente. Durante este período puede constatarse la constitución de un escenario de disputa y elevada confrontación, en el que las organizaciones sociales comienzan a motorizar las demandas de los sectores populares convirtiéndose en interlocutores válidos frente al Estado y tensionando los modos de participación política tradicionales (sindicatos y partidos políticos). Aquí comenzaba a dejar de tener eficacia la lógica de la representación, que eclosionó en 2001 con el que se vayan todos ${ }^{12}$.

Los altos niveles de desempleo, el empobrecimiento de amplias capas de la sociedad, la poca respuesta del movimiento sindical y las escasas perspectivas de cambio fueron definiendo un escenario ante el cual, muchas de las organizaciones sociales desplegaron estrategias ligadas a formas de acción directa que reconfiguraron su relación con el resto de los actores habilitando nuevos sujetos, produciendo nuevas significaciones imaginarias. En este contexto de crisis surgen las primeras recuperaciones de fábricas y empresas por parte de los trabajadores. Frente a esta situación, la estrategia de la recuperación se presenta como una alternativa para mantener la fuente laboral entre el conjunto de los trabajadores que se ven desempleados y frente a un escenario altamente desfavorable ${ }^{13}$.

\footnotetext{
11 "Por otra parte, la difusión de formas atípicas de empleo (trabajo intermitente, precario, informal) conspira contra la efectivización de acciones colectivas cuyo anclaje primario se había consolidado durante el siglo XX en la gran empresa. En este sentido, constituye uno de los efectos principales de la descolectivización que los individuos se encuentran cada vez más expuestos a enfrentar individualmente situaciones que colocan en riesgo la reproducción material y social de sus condiciones de vida (Castell, 2000)" (Wyczykier, 2009: 91).

12 "Cuando las lógicas colectivas operan en multiplicidad toman formas rizomáticas y establecen redes que multiplican acciones colectivas, por fuera de los paradigmas de la representación, donde multiplican pero nunca se repiten, mutan todo el tiempo en redes moleculares en formas organizativas que resisten delegaciones, jerarquías y liderazgos fijos" (Fernández, 2006: 259).

13 “...la situación era vivida por sus protagonistas como "última oportunidad” para evitar caer en un tipo de desocupación, que dadas las características de la crisis y la ausencia en Argentina de seguro de desempleo, ponía a dichos trabajadores y sus familias en una situación límite" (Fernández, Imaz, Calloway; 2006: 204).
} 


\section{El nuevo contexto pos 2003}

A partir del 2003, el nuevo contexto social comienza a constituir un entramado de articulaciones en el ámbito económico y político que se va a expresar, entre una multiplicidad de cuestiones, en la re-estructuración de los escenarios de disputa en el territorio de las fábricas y empresas en el cual se desarrollaron los procesos de recuperación.

A partir del año 2003, se comienza a percibir una re-significación y un mayor reconocimiento de estas experiencias en la agenda política de Estado, en el plano técnico/económico y jurídico/legal.

En el plano técnico/económico puede corroborase una mayor intervención del Estado a través de subsidios, créditos y asesoramiento, proveniente del Ministerio de Desarrollo Social y del Ministerio de Trabajo. La creación de programas y organismos orientados hacia este sector, evidencian ciertos mecanismos de legitimación de estas experiencias por parte del Estado ${ }^{14}$. Según Ruggeri (2010) en el Informe del Tercer Relevamiento de empresas recuperadas por sus trabajadores, hasta el año 2004 se percibe la ausencia de una política consistente que respalde a los trabajadores y sus empresas. Existía una dispersión de las agencias de política pública hacia las empresas recuperadas, había una incoherencia entre sí y una inexistencia del sector en la consideración de la política económica. Si bien en el período posterior algunos aspectos continúan existiendo, sobre todo en relación a la forma dispersa y a veces contradictoria de intervenir sobre este sector, la entrega de subsidios por parte del gobierno nacional comenzó a crecer. Según el relevamiento recién mencionado, a diferencia del período previo al 2004, donde un 46\% de empresas recibieron algún tipo de subsidio estatal, para el año 2010, este porcentaje se eleva a un $85 \%{ }^{15}$.

En este sentido, y a lo largo de estos años, podemos pensar que los colectivos de trabajadores de FER atraviesan un proceso de legitimación en relación al Estado que

\footnotetext{
14 En este sentido, podemos considerar la creación del Programa de Trabajo Autogestionado del Ministerio de Trabajo, el Programa Nacional del Recuperación de Empresas del Instituto Nacional de Tecnología Industrial (INTI) y el protagonismo del Instituto Nacional de Economía Social (INAES) dependiente del Ministerio de Desarrollo Social.

15 De la totalidad de las empresas relevadas, el $19 \%$ de las recibió capacitación, un 18\% recibió asesoramiento legal, un 14\% recibió planes sociales y un 32\% diversos tipos de cuestiones (apoyo político, bolsones de comida, donaciones, etc.) (Ruggeri, 2010: 109 - 110).
} 
pareciera desarrollarse de manera desigual y heterogénea con respecto a las formas en las que éste interviene.

A la hora de analizar este proceso de legitimación en la dimensión jurídica/legal, que está fuertemente ligada a la situación de la propiedad de los inmuebles, resulta relevante tener en cuenta: por un lado, los avances de una gran cantidad de unidades productivas que obtuvieron fallos a favor de las cooperativas y, por otro lado, la Reforma en el año 2010 de la Ley 24.522 de Quiebras y Concursos. Con respecto a la situación legal, desde el 2004 hasta el 2010 el porcentaje de empresas que lograron la expropiación a favor de la cooperativa fue del $65 \%$ a diferencia del período anterior donde más de la mayoría de empresas recuperadas tenía una situación legal incierta (Ruggeri, 2010).

Por otro lado, las primeras experiencias de FER entre fines de los noventa y principios del año 2000 constituyeron la recuperación de unidades productivas conformando un repertorio de resistencia novedoso de la fuente de trabajo. Eso habilitó el espacio para que surjan múltiples experiencias que confluyeron en los diferentes movimientos de fábricas y empresas ${ }^{16}$. El proceso de conformación de los movimientos permitió dinamizar las recuperaciones en el nuevo contexto. A su vez, este momento estuvo acompañado por transformaciones en los imaginarios sociales que dieron mayor visibilidad y legitimidad a estos procesos, habilitando un conjunto de herramientas que ampliaron la capacidad de lucha de los colectivos de trabajadores ante situaciones conflictivas. Así, a la hora de recuperar una fábrica o una empresa la mayoría de los colectivos de trabajadores, en estos últimos años, ha tenido rápidos asesoramientos por parte de los movimientos que nuclean a las fábricas y empresas. Habiéndose aceitado una red que permite que los trabajadores no queden aislados en su lucha.

En este sentido, tanto el apoyo de los movimientos como las experiencias de otras FER allanaron, de cierto modo, el camino a las nuevas, mostrando una forma posible y viable de organización del trabajo. Por un lado, esto promueve y legitima un proceso de lucha colectiva, permitiendo la posibilidad de la invención de un nuevo proyecto. Por otro lado, muchas veces esto resulta ser un límite a la hora de pensar nuevas formas de organización en un colectivo de trabajadores, quizás porque se restringen a repetir

\footnotetext{
${ }^{16}$ Por ejemplo el Movimiento Nacional de Empresas Recuperadas (MNER), el Movimiento Nacional de Fabricas Recuperadas (MNFR), Federación Argentina de Cooperativas y Trabajadores Autogestionados (FACTA), Asociación Nacional de Trabajadores Autogestionados (ANTA), Unión Productiva de Empresas Autogestionadas (UPEA).
} 
modalidades que han creado otras fábricas y empresas. Un ejemplo de eso es lo que sucede con los escasos reglamentos escritos que existen en estas unidades productivas, muchos de ellos se han redactado tomando como modelo reglamentos de cooperativas más antiguas.

En estos últimos años, los canales de diálogo y la participación del Estado en este sector ha permitido, en muchos casos, resolver ciertas problemáticas que presentaban las FER. El apoyo técnico y económico en determinadas unidades productivas abrió las condiciones de posibilidad para una mayor y mejor producción. De esta forma, los préstamos otorgados por algunas dependencias estatales permitieron a dichas fábricas y empresas la compra de nueva maquinaria, generando mejores condiciones de competitividad en el mercado.

Sin embargo, la posibilidad de constituirse como cooperativas según las normas del INAES lleva a aceptar y aplicar ciertas formas jurídicas y organizativas que no se adecuan a las características especificas en relación a los modos organizacionales que estos colectivos se dan a sí mismos.

Otra modalidad de intervención desde organismos del Estado consiste en el gerenciamiento estatal en las FER donde especialistas realizan funciones de coordinación y organización. Sobre esto una trabajadora nos decía:

\begin{abstract}
La cooperativa está siendo gerenciada por personas que trabajan en el INAES y por un grupo de contadores que ya tienen experiencia en empresas recuperadas $(\ldots)$ El gerenciamiento lo que hace es unir toda la información y semanalmente se hacen charlas entre los responsables de área y se comunican las noticias, las cosas buenas y malas para que después ellos se lo trasmitan a cada uno de los compañeros. Esto a nivel a financiero, a nivel social. (Yanina, trabajadora de industria gráfica).
\end{abstract}

El gerenciamiento, el asesoramiento técnico, el apoyo económico y el marco legal propiciado por el Estado expresan el modo en que éste pretende instituir un modelo organizacional que se adecue con las lógicas ya prefiguradas, configuradas desde esferas por fuera de la propia práctica autogestionaria. Esto responde a una lógica de la representación ${ }^{17}$ en las FER que, por un lado, facilita a los colectivos las difíciles tareas

\footnotetext{
17 "Pensamos que en todo colectivo- sea un pequeño grupo, un grupo amplio, una multitud, etc.- operan lógicas de multiplicidad y lógicas de representación. Los sistemas de delegación, los partidos políticos, el Estado, las instituciones, etc. capturan, dan forma, disciplinan, organizan, cercan, las lógicas magmáticas de multiplicidad manteniendo capturada, territorializada, segmentarizada, la potencia de estos colectivos que operan por la delegación tanto de su capacidad de invención imaginante como de sus acciones. Esta es una de las modalidades capitalistas de mantener la fábrica en orden; también hace posible que la vida política de una sociedad sólo sea tarea de la clase política.” (Fernández, Borakievich, 2007: 4).
} 
de administración de la unidad productiva, pero por otro lado, genera un cerco de sentido en potenciales prácticas inventivas en los modos de autorregulación de los trabajadores.

De esta manera, con la intervención del Estado, como de los movimientos de FER, insiste la misma tensión, la tensión entre las lógicas colectivas de la representación y las lógicas colectivas de la multiplicidad ${ }^{18}$. Las fábricas recuperan potencia autogestiva cuando aceptan los apoyos del Estado y los movimientos sin adherir completamente a esas formas ya constituidas, desmarcándose en acto de la lógica de lo Uno, recuperando la capacidad de invención en la singularidad de sus recorridos.

\section{La autorregulación: sus procedimientos e instrumentos}

Lo que insiste y parece perdurar, tanto en el contexto anterior como en el actual, es la transformación en sus posicionamientos subjetivos. Cada uno de los trabajadores tuvo que aprender nuevas funciones dentro de la fábrica o empresa, pero por sobre todo tuvo que aprender el difícil ejercicio de decidir, de tener voz, de hacerse responsable: el hecho de asumir la autogestión. Algo que de alguna manera como obrero de una fábrica con patrón tenía vedado, sólo por su hábitus de clase. Mediante prácticas autogestivas lograron implementar nuevos procedimientos de autorregulación y también tensar los modos históricos de subjetivación propios de la disciplina fabril tradicional (Calloway, 2010).

Históricamente las fábricas y empresas bajo patrón se han organizado a partir de una disciplina fabril tradicional donde la verticalidad de mando y transmisión jerárquica de normas se constituyen como los principales procedimientos de control y disciplinamiento de los trabajadores. Una vez que el patrón ya no está, y el colectivo de trabajadores comienza a autogestionarse, es válido preguntarse cuáles son esos procedimientos e instrumentos que caracterizan al proceso de regulación del trabajo en las FER.

\footnotetext{
18 "Por multiplicidad no se entiende el muchos de lo Uno, ni el rechazo de identidades y totalizaciones sino que aquello que escapa a dualismos y binarismos generalmente reductivos, que incita a pensar desde lógicas no disyuntivas, desde el Y y el "entre"; no se trata de "pensar una multiplicidad como lo que tiene muchas meras adiciones de partes sino como lo que esta plegado de muchas maneras". La multiplicidad es el don de lo diverso, de las diferencias que retornan como intensidades que se repiten configurando plexos de relaciones rizomáticas" (Fernández, 2006: 258-259)
} 
A partir del trabajo de campo realizado, relevamos en el proceso de gestión de estas cooperativas distintos procedimientos de autorregulación que se manifiestan: 1) a través de prácticas que incentivan o sancionan determinados comportamientos, 2) a través del modo de incorporación de nuevos trabajadores, 3) en las modalidades y dinámicas asamblearias.

\section{1) Incentivos y sanciones}

Con respecto a aquel conjunto de prácticas que buscan sancionar e incentivar los comportamientos de los trabajadores podemos clasificarlos en procedimientos de autorregulación negativos y positivos (Imaz, Calloway, Cabrera, 2008).

Entendemos por procedimientos de autorregulación negativos a aquellas prácticas que operacionalizan determinados instrumentos para sancionar las faltas de trabajadores frente a los criterios y las normas que los trabajadores deciden colectivamente.

A diferencia de las fábricas y empresas bajo patrón, la aplicación de dichas medidas se realiza en última instancia, donde el diálogo entre compañeros resulta ser el primer recurso para buscar el cambio en las conductas de orden individual que afectan al colectivo de trabajadores. En líneas generales las diferentes estrategias, que apuntan a concientizar y transformar ciertas conductas que incumplen las normas, son establecidas en conjunto por el colectivo de trabajadores previamente a la aplicación, recayendo en todos y cada uno la responsabilidad de la aplicación de las medidas:

\footnotetext{
-Acá hubo problemitas con las faltas, las llegadas tardes. Nosotros lo que hacemos con un caso así, te llamamos, si te tenemos que llamar una segunda vez, te llamamos. Si te tenemos que llamar una tercera, te llamamos. -¿Quién es el encargado de llamar?

-El Consejo. Los llamamos, les explicamos. Si reincidís en lo mismo, te va a costar una suspensión. (Juliana, trabajadora de industria metalúrgica)
}

Lo que se prioriza aquí es el vínculo que se establece entre los compañeros, que resulta una de las aristas fundamentales a la hora de la producción bajo la modalidad autogestiva y horizontal:

Si llegamos tarde hay un descuento en el sueldo. Pero no nos enfocamos tanto sobre el descuento. Acá pasa más por lo humano, si llegás tarde le dejás más trabajo a otro y no da (...) Nos enfocamos en que si llegamos tarde le vamos a dar más trabajo al que está al lado. Pasa por la responsabilidad. (Carlos, trabajador de industria metalúrgica) 
Ante esta situación, la interpelación a estos trabajadores a través de charlas personales es un procedimiento utilizado frecuentemente para poder llegar a solucionar las situaciones particulares que llevan a tales conductas. Muchas veces estas charlas son propiciadas por trabajadores que ocupan lugares en el consejo de administración y la presidencia de la cooperativa y son utilizadas como un recurso previo a la aplicación de algún tipo de sanción. Así, la sanción aparece como un último recurso ante la imposibilidad de transformar las conductas que afectan al colectivo. Si bien la sanción es un instrumento utilizado también en empresas y fábricas bajo patrón, los procedimientos en las FER bajo los cuales se aplican las sanciones resignifican este tipo de instrumento. En este sentido, la decisión de implementar una sanción es del conjunto de trabajadores más allá de que muchas veces la aplicación recaiga en el consejo de administración.

De esta manera, los procedimientos de autorregulación "negativos" implican la utilización de instrumentos que parecieran ser los mismos a los implementados en las empresas y fábricas bajo patrón. Sin embargo, en tanto las modalidades de aplicación difieren profundamente en las FER a partir de las formas en que son transmitidas, comunicadas y a la capacidad de comprensión ante ciertas situaciones, es que se puede afirmar que las lógicas que rigen los modos de regulación ante situaciones que perjudican al colectivo en estos espacios son sumamente diferentes. El escenario de relaciones sociales que implica la autogestión en estos espacios lleva a la implementación de este tipo de prácticas resiginificando los instrumentos tradicionales de regulación de las empresas y fábricas bajo patrón.

Un ejemplo de los mecanismos de las empresas bajo patrón que perduran en las FER es, en aquellas unidades productivas de mayor número de trabajadores (más de 100 trabajadores asociados):

Hasta hace 6 meses tal vez la cooperativa era más flexible con las horas. Pero al haber tantas personas, siempre hay alguien que no cumple, su responsabilidad no está a la par de los compañeros que si cumplen. Entonces para que todo sea más equitativo para todos, decidimos poner un reloj. Hay unos minutos de gracia. Un reloj digital. Tenés un tiempo para llegar tarde.

En la empresa fallida ya estaba. Después se armó la cooperativa, se sacó el reloj, decidimos que cada uno venga y cumpla sus 8 horas. Pero al haber tantas personas en algún momento se pierde ese control. Entonces se armó un fichero. Pero, hecha la ley hecha la trampa, venía otro compañero y te marcaba. Entonces volvimos a poner el reloj digital (Yanina, trabajadora de industria gráfica). 
Se podría pensar aquí que el número de trabajadores pareciera configurar una dinámica diferente a la hora de la conformación del colectivo. Pareciera que a mayor número se perdería algo de lo que aporta el vínculo cara a cara ${ }^{19}$ (Rebón, 2006).

Al ser una cooperativa tan grande, hay focos de personas con las que hay que trabajar, hay que hablarles, transmitir que empujamos todos para el mismo lado, no depende de un patrón sino de todos (...) tal vez en un grupo más chico estas cosas se van notando menos. (Vanina, trabajadora de industria gráfica).

Entendemos como procedimientos de autorregulación positivos aquellas conductas que tienen la función de incentivar mejores prácticas laborales y favorecer la producción, así como también la cohesión del colectivo de trabajadores. Estos procedimientos tienen la finalidad de recompensar las conductas que encarnan los valores propios del cooperativismo tales como la responsabilidad, la solidaridad y el compromiso en las funciones que los trabajadores cumplen.

En este sentido, observamos que algunas fábricas han resuelto distribuir un porcentaje del excedente bajo la modalidad de premios al presentismo:

Siempre remarcábamos en la asamblea el tema del ausentismo. Había un premio a la puntualidad para que no hubiese tanto ausentismo. Había compañeros que decían yo vengo todos los días y cobro lo mismo que el compañero que no vino. Claro porque el compañero que no venía traía el justificativo médico. Vos le pagás porque te trajo el justificativo, pero gana lo mismo que ganás vos que viniste todos los días. Ahora lo que implementamos es el premio de excedente. Cuando llega fin de mes se ve qué hubo de facturación, si hubo ganancia se reparte la ganancia por partes iguales. La mitad queda para la cooperativa, y la mitad queda para los asociados. Si vos faltaste porque quedaste enferma, el día ese que faltaste en el premio de excedente no lo cobrás. A partir de esto, el tema de las ausencias comenzó a corregirse muchísimo. (Juliana, trabajadora industria metalúrgica).

Otras han decidido otorgar pequeños créditos para aquellos trabajadores que mantengan un buen desempeño laboral:

Los otros días decidimos hacer un fondo de 40000 pesos para darles préstamos a los compañeros. Cada compañero tiene un tope de 8000 pesos. ¿Por qué? Porque nosotros no tenemos recibo de sueldo y nadie puede ir a pedir un préstamo a ningún lado. Vino un compañero y me pide 8000 pesos. Durante veinte semanas te vamos a descontar 400 pesos (Juliana, trabajadora de industria metalúrgica).

19 “(...) cuando las organizaciones crecen en número de asociados y llegan a ser multitudinarias el anonimato reemplaza las relaciones interpersonales particularísticas, aparte de que los cargos elevados confieren prestigio cuando se trata de entidades grandes y exitosas" (Bonaparte, 1994: 37). 
Estos incentivos no dependen exclusivamente del buen desempeño laboral, sino que también contemplan la situación particular y las necesidades de cada trabajador. Así, el colectivo coopera con las necesidades de los asociados que más lo requieran.

\section{2) Procedimientos de incorporación de nuevos trabajadores}

Otro de los procedimientos de autorregulación tiene que ver con los procedimientos de incorporación de nuevos trabajadores a la cooperativa. Los criterios de selección y las prácticas implementadas en la incorporación de trabajadores definen los procedimientos que el colectivo utiliza para que aquellos nuevos trabajadores puedan integrarse de un modo satisfactorio a las lógicas de trabajo que implica un ámbito autogestionado. Esto supone integrarse al proceso de trabajo en relación al puesto, las responsabilidades y las dinámicas horizontales de gestión que caracterizan a estos espacios. Por lo cual, los procedimientos que los colectivos de trabajadores lleven a cabo en la incorporación, se constituyen en mecanismos fundamentales para la autorregulación de las FER.

A través de los modos de selección y admisión de nuevos trabajadores el colectivo establece los perfiles de aquellos sujetos que pasarán a formar parte del emprendimiento primando valores que difieren muchas veces de aquellos que caracterizan a los criterios de incorporación utilizados en empresas y fábricas bajo patrón.

Los principales criterios de incorporación de nuevos trabajadores tienen que ver con priorizar los lazos familiares o de amistad. Hijos, sobrinos, primos, amigos desempleados, encuentran en la cooperativa un espacio para volver o empezar a trabajar. En este sentido, el criterio que prima en estos casos tiene que ver con suponer que la incorporación de familiares o amigos llevará a construir relaciones basadas en una mayor confianza y responsabilidad que favorezcan el fortalecimiento de la cooperativa. En los emprendimientos bajo patrón los criterios que suelen primar están relacionados con los conocimientos y el "saber hacer" según lo que requiera el puesto.

Dadas las características que adoptan las FER en relación a la producción (que implica muchas veces asumir mayores tareas que las del puesto) y las dificultades que se derivan de la situación jurídica de muchas de ellas (sobre todo en relación a la propiedad de los inmuebles) llevan, entre otras cosas, a este tipo de cooperativas a requerir de equipos de trabajo fuertemente consolidados donde la confianza, la 
responsabilidad y la ayuda mutua se conviertan en pilares de dichas organizaciones para poder afrontar y superar las dificultades que atraviesan:

Básicamente, se pude decir que el eje es la responsabilidad. Asumir la responsabilidad. Sigo creyendo que el eje pasa por ahí. La diferencia básica de una empresa recuperada y otra con patrón es la responsabilidad, esa es la base. Aún en detrimento del bolsillo (Gonzalo, trabajador de industria maderera)

Es por esto que la incorporación de sujetos confiables y "familiarizados" con este tipo de experiencias se constituye en uno de los procedimientos que permitirían una mejor autorregulación de los procesos de trabajo.

La incorporación no implica el solo hecho de comenzar a trabajar en la cooperativa sino que la incorporación debe ser pensada como un proceso en el cual el colectivo utiliza determinados procedimientos que aseguren una efectiva asimilación de las tareas del puesto y de las responsabilidades que implica el "ser socio" en un ámbito cooperativo. El problema que surge del modo en que se incorpora a los trabajadores en los casos estudiados es que la transmisión de la historia de cada experiencia y de lo que implica el trabajo de forma cooperativa se da de forma poco sistematizada por lo cual el proceso de incorporación de cada trabajador queda librada a las charlas informales que estos puedan tener con aquellos trabajadores "históricos" de cada espacio:

Yo les hago una explicación de todo esto, los pongo al tanto de dónde va a venir. Pero hay muchos que están al tanto porque son familiares o ex trabajadores. Pero algunos no tenían nada que ver, que teníamos que llamarlos porque necesitamos cubrir el puesto. Pero hablando con estos compañeros me di cuenta que no entienden del lugar, que cuando consigan algo en relación de dependencia se van (Daniel, trabajador de industria textil).

En este sentido, la mayoría de los trabajadores poseen largas trayectorias laborales bajo relaciones de dependencia mientras que en algunos casos apenas tienen experiencia en el mundo del trabajo, por lo cual, el ingreso a ámbitos de trabajo caracterizados bajo lógicas autogestivas provocan tensiones en los modos de subjetivación de estos trabajadores. A la vez, implica un desafío grande para la cooperativa ya que el modo en que estos trabajadores se incorporen va impactar fuertemente en el proceso de trabajo. 


\section{3) Modalidades y dinámicas asamblearias}

Las asambleas son espacios de debate y decisión, pero también espacios en los que se dan las condiciones para la innovación y la creación. Son dispositivos que permiten multiplicar sus discusiones más allá de ellos mismos, en los que siempre hay lugar para alojar lo inesperado y lo diverso. Son espacios democratizantes, ya que suponen una instancia de diálogo, pero no son neutrales, allí se visibilizan tensiones y relaciones de poder.

Las FER se han valido de la asamblea como herramienta de construcción de autogestión y de horizontalidad. Las mismas han sido constitutivas de la experiencia, han sido los espacios en los que se decidió llevar a cabo la ocupación y las estrategias de resistencia, los criterios de incorporación de nuevos socios, las reglas internas del colectivo, el destino de los excedentes y el monto de los retiros. En las FER, este dispositivo permite la legitimación de un cuerpo normativo que regula el funcionamiento de la empresa y que no necesariamente queda plasmado en un estatuto o reglamento. La mayoría de las empresas relevadas no cuentan con un estatuto elaborado por el mismo colectivo de trabajadores.

La asamblea funciona en este caso como un dispositivo para el nacimiento de la ilusión grupal (Fernández; 1989), permitiendo una proyección conjunta de un futuro deseado. Allí se crean conjuntamente las significaciones imaginarias que estructuraran al colectivo autogestivo, habilitándolo como espacio para la proyección de objetivos comunes y de crecimiento conjunto.

En función de su modalidad y dinámica, la asamblea se constituye en una variable imprescindible a la hora de definir los procedimientos de autorregulación característicos de cada FER. Así, la forma de funcionamiento de cada asamblea varía en función de la experiencia de cada espacio, evidenciando las formas en las que se toman las decisiones y los grados de horizontalidad en cada organización.

En este sentido, las modalidades asamblearias pueden ser comprendidas a partir del manejo de información, su acceso y circulación, mientras que las dinámicas asamblearias tienen que ver con la frecuencia, el nivel de participación y la disposición en el espacio. 
La información es un recurso sustancial en toda organización, pero esta no se distribuye homogéneamente. Así podríamos decir que cuanto mayor el grado de distribución de información mayor será el grado de horizontalidad de la organización. La asamblea es uno de los espacios formales de comunicación de información. En este sentido, como dijimos anteriormente, la asamblea es un espacio democratizante. Allí pueden presentarse una serie de temas a ser abordados y, por más que al interior de la asamblea puedan existir formas de comportamiento pautadas o una serie de reglas (explicitas o implícitas), no todo está determinado ya que los sujetos poseen ciertos márgenes de libertad de acción. Al mismo tiempo, los debates acerca de diferentes cuestiones que atraviesan a las fábricas y empresas escapan a los espacios asamblearios.

Estas discusiones aparecen en los pasillos, en la cocina, en los almuerzos, discusiones que llevan a un "estar asambleario"20, que por momentos parece permanente. Es en esos momentos en los cuales se van debatiendo problemáticas que parecen llegar al espacio específico de la asamblea con una forma, con una discusión previa. Podríamos pensar que este estar asambleario se da en los momentos de mayor conflicto de las recuperadas, ya que según los dichos de uno de los trabajadores, cuando el conflicto desaparece (o se adormece, ya que siempre está latente) parece "plancharse" este estar asambleario y el debate queda reducido a los espacios estrictamente designados para tal propósito.

En este sentido, podríamos plantear dos modalidades asamblearias que no necesariamente son excluyentes y que varían en función de las circunstancias: 1) aquella en la que la asamblea gira en torno a lo productivo y donde esta funciona como un espacio para la rendición de cuentas. Este tipo de modalidad asamblearia tiene un carácter informativo e intenta garantizar la transparencia de "los números". En este tipo de modalidad de asamblea no se vota y dichas temáticas resultan ser lo convocante para los trabajadores. 2) El otro tipo de modalidad ahonda en cuestiones que no son exclusivamente productivas, como por ejemplo el fortalecimiento de lazos con otras

\footnotetext{
20 "Otra característica que se observa es que por fuera de la asamblea que se establece con cierta regularidad -de acuerdo a cada fábrica- se produce una suerte de estado asambleario en el cual las discusiones se desarrollan en todo momento en los pasillos, en los descansos, las comidas, en la cotidianeidad, de modo tal que el tratamiento de los temas no se restringe al espacio propiamente asambleario sino que se da una suerte de debate o deliberación que incluye los espacios informales, los tiempos de producción y de descanso". (Fernández, Imaz y Calloway, 2006: 217).

Con el paso del tiempo, hemos considerado que la palabra estado remitiría a cierta significación ontologizante que no permitiría pensar el devenir singular de los sucesos en estos colectivos, es por esto que lo denominamos actualmente estar.
} 
fábricas y empresas recuperadas, la relación con otros espacios que funcionan dentro de las fábricas ${ }^{21}$ y los modos de organización del trabajo. Aquí la asamblea funciona como germinal político, permitiendo alojar lo inesperado, propiciando la construcción de lógicas colectivas de la multiplicidad (Fernández; 2007). El debate en conjunto otorga un plus irreductible a la suma de sus integrantes (Fernández, 1989). De allí pueden surgir las más variadas gamas de alternativas y formas de llevarlas a cabo. En este sentido, la asamblea podría funcionar como una suerte de incubadora, de germinal de diversidades que pueden desbordar lo establecido. En este tipo de modalidad asamblearia se vota y gana la posición con mayor cantidad de votos y esta decisión se acata y toma un carácter resolutivo.

La dinámica asamblearia también puede ser pensada como un procedimiento de autorregulación a partir de la frecuencia con la que se realizan. Entendemos que esto tiene que ver con el nivel de comunicación interna de una organización, la voluntad de participación de los sujetos en los posibles espacios de intervención (su implicación) y los niveles de cohesión del colectivo (aunque no necesariamente una mayor frecuencia en la realización de las asambleas supondría todo lo anterior). En algunas de las fábricas visitadas las asambleas se realizan mensualmente: "Tenemos pautado que una vez por mes la hacemos. Entre los primeros diez días del mes donde también presentamos el informe económico (...) antes se hacían más seguido" (Daniel, trabajador de industria textil).

En otras empresas las asambleas se realizan más esporádicamente: "Cada 3 o 4 meses hay una asamblea informativa, donde no se vota. Es informativa". (Carlos, trabajador de industria metalúrgica).

Una mayor frecuencia en la realización de la asamblea fortalece el vínculo entre los trabajadores a partir de un mayor nivel de intercambio de información y opiniones acerca de las situaciones que atraviesa la cooperativa.

Por otra parte, el interés por participar o no en la asamblea podría estar dando cuenta por un lado, del sentido que le atribuyen los sujetos, es decir, del nivel de utilidad o credibilidad que le otorgan y al mismo tiempo, del nivel de implicación o interés del colectivo de trabajadores con respecto al espacio. En algunas fábricas las asambleas tienen un carácter obligatorio y se realizan fuera del horario laboral:

\footnotetext{
${ }^{21}$ Algunas fábricas y empresas han cedido espacios dentro de sus instalaciones de forma permanente para la apertura de centros culturales, radios y distintos tipos de espacios educativos.
} 
-Las asambleas se realizan a final de mes y es después del horario laboral.

$-¿$ Y van todos?

-Si, es obligatorio. Tenés que ir, uno lo toma como una obligación, es como un acto disciplinario, yo sé que el día de la asamblea tengo que estar (Juliana, trabajadora de industria metalúrgica).

En otras fábricas las asambleas se realizan en el horario laboral y aún así los niveles de participación son bajos:

Si, acá es a las 14 hs. en día y horario laboral, pero muchos no participan, muchos se van antes que termine. Hablamos de cómo intentar regular eso. A corto plazo lo vamos a hacer. No hay nada escrito que deje claro que hacer con el que no va o con el que se va antes (Daniel, trabajador de industria textil).

Como mencionamos anteriormente, los espacios asamblearios son constitutivos de la experiencia de las FER. Es el espacio en donde puede decidirse qué hacer y cómo hacerlo, donde se resuelven problemas e inquietudes y de dónde emergen los procedimientos de autorregulación que permiten el funcionamiento de la unidad productiva. Las decisiones que de allí surjan se valdrán de la legitimidad del colectivo de trabajadores. En este sentido, la asamblea es un espacio de vital importancia en donde se resignifica el espacio de trabajo y donde se asume la autogestión:

Tiene que ver con la subjetividad, la gente que participa en la asamblea entiende donde está trabajando pero la mayoría de la gente trabajo 30 años de su vida en relación de dependencia y es difícil cambiar la cabeza (Daniel, trabajador de industria textil).

Esta resignificación del trabajo es parte de un proceso interno de cada trabajador en el que el colectivo acompaña y posibilita esta transformación subjetiva. Por otro lado, en relación a la utilización del espacio y su distribución, algunas asambleas se distribuyen en el espacio remarcando las diferencias jerárquicas que ya se dan en el día a día en la fábrica, por ejemplo, aquellas asambleas en la que los trabajadores de planta se sientan mirando hacia al frente en el que se ubica la comisión directiva: “¿Cómo se ubican en la asamblea? Como en el cine, adelante una mesa con los directivos" (Carlos, trabajador de industria metalúrgica).

Así quedan diferenciados aquellos puestos con mayor jerarquía reproduciendo la diferencia que se da día a día al interior de la asamblea. Esta forma de ubicarse en la asamblea continua remarcando y potenciando la diferencia entre los operarios de planta 
y los puestos de oficina reproduciendo la misma diferenciación en la forma organizativa de las fábricas pre-recuperación.

Otras asambleas intentan disminuir estas diferencias, no reproduciéndolas al interior de la asamblea. Así, la distribución circular intenta igualar al colectivo colocando a los trabajadores en la misma situación, facilitando la circulación de miradas y gestos ${ }^{22}$.

Así la asamblea se constituye en un espacio de visibilidad de las relaciones que se establecen al interior del colectivo de trabajadores permitiendo detectar problemas y/o potencialidades al interior del mismo y habilitar el espacio para la creación de soluciones, propuestas y alternativas innovadoras. El modo en que circula la información, es una cuestión fundamental a la hora de pensar las tensiones entre horizontalidad y verticalidad en una organización. La dinámica de la asamblea puede visibilizar la forma en que fluye la información al interior de una organización, los roles y trayectorias de sus actores. De esta manera, las modalidades y las dinámicas asamblearias definen las prácticas en que los colectivos de trabajadores establecen los procedimientos de autorregulación de cada espacio.

\section{Posicionamientos subjetivos}

La salida a la desocupación como amenaza y al desempleo como disciplinamiento fue conjunta, llevo al nacimiento de lo que parecía ser un nuevo actor social: el colectivo de trabajadores de FER. Esto dió lugar a una modalidad de trabajo más horizontal, sin patrón, de manera autogestiva. El desafió de las FER era a partir de allí la capacidad de ser productivas, de ser eficaces en un mercado capitalista, algo que a más de diez años del inicio de este fenómeno lo han demostrado ampliamente.

Cada uno de los trabajadores tuvo que aprender nuevas funciones dentro de la fábrica o empresa, pero por sobre todo tuvo que aprender el difícil ejercicio de decidir, de tener voz, de hacerse responsable. Algo que de alguna manera como obrero de una fábrica con patrón tenía vedado, sólo por su habitus de clase.

Ante la violencia del sistema con su expulsión social ellos pudieron responder, como diría Ulloa (1995), con la institución de la ternura como fundante de estas nuevas

\footnotetext{
22،“(...) juegos de mirada que desencadenaran resonancias fantasmáticas y harán posibles, o no, procesos identificatorios y transferenciales; juegos de mirada que afectan y desafectan los cuerpos en sus juegos productivos de deseo y poder" (Fernández, 1989: 141).
} 
instituciones. En las cuales lo que prima es la solidaridad. Un trabajador decía: "Hacia adentro somos una milia, hacia fuera somos una empresa que compite con las demás, salvo que encontremos a otra cooperativa, con ella no competimos" (Gonzalo, trabajador de industria maderera)

Con esto aparece la conmoción de la constitución de una identidad ligada a un puesto de trabajo, comienzan las transformaciones en los términos laborales y contractuales y así también se comienzan a producir las transformaciones en el ámbito de la subjetividad.

La modalidad de cooperativa que han adoptado estas fábricas y empresas, en forma general, no hace más que reafirmar los lazos solidarios que fueron tendiéndose en casi todas ellas entre los trabajadores/as, en parte porque muchos de ellos han padecido situaciones muy duras tanto con sus antiguos patrones, como económica y legalmente en el proceso de recuperación.

De alguna manera esto parece la contracara de cómo se establecen las relaciones humanas en ámbitos laborales en la actualidad, bajo el primado de la lógica competitiva. En cambio entre estos trabajadores, en general, logran establecerse lazos solidarios y de cooperación en donde prima el colectivo de trabajo por sobre las individualidades (esto lo podemos decir en líneas generales ya que es necesario hacer la salvedad que en las FER existen conflictos internos en las relaciones humanas al igual que en todas las instituciones existentes, de cualquier manera, generalmente son otras las propuestas y procedimientos para solucionar dichos conflictos).

Así también se puede decir que muchas de estas FER han podido establecer comunicación con otras recuperadas, logrando una producción relacional que enfatice la participación abierta. También muchas de ellas han podido establecer redes en el barrio en el que se encuentran generando lo que un trabajador de una empresa recuperada denomina "arraigo social". Desafiando a la individualización creciente que podemos ubicar como una característica fundamental de la modernidad tardía ${ }^{23}$.

Se puede decir que esta modalidad de comunicarse, de establecer lazos que van construyendo en el cotidiano tiene efecto en la constitución de la subjetividad generando transformaciones en la misma. De cualquier manera este proceso no es parejo y se da de forma singular en cada uno de los trabajadores.

\footnotetext{
${ }^{23}$ Según Gilles Lipovetsky denominada "la segunda revolución individualista".
} 
El haber soportado ocupaciones difíciles en algunas fábricas y empresas parece haber sido una de las claves para armar la amalgama del colectivo de trabajadores. Fábricas y empresas que ya no eran habitadas por obreros que responden a los hábitus propios de clase, sino por colectivos de trabajadores que en la trama de constitución de los mismos lograron transformar los posicionamientos subjetivos de cada uno.

Así también a medida que ingresan nuevos socios en las fábricas y empresas recuperadas, la fábrica en sí se va transformando, va mutando en sus configuraciones organizativas. Como veremos un problema que insiste aquí es la escasa conciencia de a qué lugar están ingresando a trabajar los socios nuevos. El "clic interno· que se produce en los "viejos" socios con la ocupación y resistencia a los desalojos produce, en muchos de ellos, un nuevo posicionamiento subjetivo. Este nuevo posicionamiento se puede describir, en líneas generales, según las insistencias en las entrevistas a los trabajadores, desde diferentes aspectos: en el ámbito laboral han iniciado un ejercicio de tomar decisiones, de participar en el proceso productivo total, de manejarse con proveedores y con diferentes instituciones. Así también muchos de ellos han iniciado un camino en la militancia partidaria, barrial o asamblearia. En sus vidas familiares, muchos de ellos, se enorgullecen de considerarse ahora un ejemplo de lucha y trabajo ante sus hijos o parejas.

En los nuevos socios ese nuevo posicionamiento comienza a estructurarse en función de las nuevas lógicas que construye el colectivo de trabajadores. Es por esto que es uno de los debates en las FER, en palabras de algunos trabajadores el problema se resume en: cómo "producir conciencia", cómo generar un proceso de apropiación del proyecto y de incorporación al colectivo de trabajo.

\section{Algunas reflexiones finales}

En el proyecto presentado al inicio de esta investigación, uno de los objetivos planteados era la indagación sobre algunos instrumentos de autorregulación como los estatutos y reglamentos. A partir de los relevamientos de campo nos encontramos con la ausencia de reglamentos en las unidades productivas que fueron indagadas, tanto las que se recuperaron previo a 2003 como las que lo hicieron posteriormente a este año.

Los procedimientos de autorregulación descriptos líneas arriba en este trabajo, conforman un marco normativo no materializado en ningún documento, aunque se 
explicita en la práctica cotidiana y tiene su legitimidad en la asamblea. El conjunto de normas que lleva adelante el colectivo de trabajadores en la mayoría de los casos son discutidas y consensuadas en el dispositivo asambleario, y muchas veces aplicadas por los consejos de administración. En consecuencia notamos cierta dificultad en poder plasmar en papel dichas pautas que permitirían la materialización del resultado de las discusiones y acuerdos colectivos; cristalizando los criterios de organización y funcionamiento.

Consideramos que esto podría responder a múltiples causas. Una de ellas podría ser un cierto temor a instituir ciertas pautas y normas, con el riesgo de que esto reproduzca la disciplina fabril tradicional, con la que los trabajadores han sufrido tanto.

Así mismo otra de las aristas difíciles es la aplicación del conjunto de normas, que si bien fueron consensuadas colectivamente, muchas veces su aplicación recae en uno o varios de los miembros del consejo de administración, con el riesgo de que resulte una sanción de orden personal. O que se confunda a la persona que está aplicando la norma con la antigua figura del patrón. Aquel que lleva a la práctica la medida está sancionando a un compañero, con el que probablemente haya compartido una serie de situaciones difíciles en lo laboral, en la lucha, o en la ocupación. Consideramos que este vínculo que se forja a lo largo del devenir propio del colectivo dificulta en cierta manera la aplicación de normas, más allá que todos los trabajadores tengan conocimiento de ellas.

Los procedimientos normativos en forma escrita en papel parecieran correr el riesgo de universalizar una forma de autorregulación. Consideramos que esto traería aparejado una suerte de despersonalización, que dificulataría el objetivo final de la sanción que es el de visibilizar la falta hacia aquello consensuado por todos. Así, en el caso de las FER, antes de llegar a la sanción se da comienzo a una serie de conversaciones, de encuentros, donde lo que prima es la reflexión, el volver a contextualizar el sentido que asume la falta en el espacio. Estas conversaciones, quizás más informales, ocurren antes de aplicar cualquier tipo de sanción.

Podemos pensar que el germinal político del inicio de los años noventa, que resistía a toda lógica de la representación, en un apartado anterior, continúa insistiendo en los emprendimientos productivos indagados. Podemos ver en la ausencia de reglamentos escritos una modalidad de resistencia más a las lógicas de la representación. 
Los colectivos de trabajadores parecen defender en su resistencia las lógicas de la multiplicidad, que se operacionalizan en la autogestión y horizontalidad de la organización del colectivo. Los trabajadores parecen transitar en forma permanente la tensión existente entre las lógicas de la representación y las lógicas de la multiplicidad.

Esta misma problemática se despliega en la relación de las FER con el Estado. Al mismo tiempo que se aceptan formas de intervención estatales para la organización y el desarrollo de la producción, conformándose como cooperativas de trabajo, ya que esta es la condición que impone el Estado para entrar en el mercado laboral, continúan en la práctica cotidiana dándose a sí mismos modalidades de autorregulación y organización singulares.

El interrogante de aquí en adelante será cómo continuará la relación de las FER con el Estado. El desafío será, quizás, seguir manteniendo vínculos puntuales, no uniformarse en sus normativas, y al mismo tiempo poder sostener la capacidad de invención del colectivo que será aquello que potencie la autogestión.

\section{Referencias}

BONAPARTE, H. "Frente al neoliberalismo: ¿cooperativas posmodernas?”, Centro Editor de América Latina, 1994.

CALLOWAY, C. "La regulación colectiva en las fábricas y empresas recuperadas por los trabajadores/as". En memorias del Cuarto encuentro de investigadores en Psicología del MERCOSUR. U.B.A, 2008.

"Desafíos en los procedimientos de autorregulación en las fábricas y empresas recuperadas". En Memorias de II Jornadas Internacionales de Problemas Latinoamericanos. Movimientos sociales, procesos políticos y conflicto social: escenarios en disputa. CONICET UNC, 2010.

CENDA, "La Macroeconomía después de la convertibilidad”, Buenos Aires, 2010.

FAJN, G. Fábricas y empresas recuperadas. Ediciones del Instituto Movilizador de Fondos Cooperativos. Centro Cultural de la Cooperación. Buenos Aires, 2003.

"Empresas en crisis: autogestión de sus trabajadores", en Revista de la Cooperación internacional, Vol. 36, № 2. Ginebra, Suiza, 2003.

FERNÁNDEZ, A. M. “El campo grupal”. Nueva Visión, Buenos Aires, 1989.

Política y Subjetividad. Asambleas barriales y fábricas recuperadas. Tinta Limón ediciones. Buenos Aires, 2006. 
"Las lógicas colectivas: imaginarios, cuerpos y multiplicidades". Editorial Biblos, Buenos Aires, 2007.

"La Anomalía Autogestiva", en Memorias del Primer encuentro internacional de debate: La Economía de los trabajadores y la distribución de la riqueza. Bueno Aires. Julio, 2007.

HUDSON, J.P. Empresas Recuperadas por los Obreros: Fin de Etapa y Nuevas Instituciones.En revista $n^{\circ} 5$ del OSERA (Observatorio Social de Empresas Recuperadas y autogestionadas), Buenos Aires, 2011.

IMAZ, X.; CALLOWAY, C. y CABRERA, C. "Los desafíos de la autogestión en las fábricas y empresas recuperadas". IV Jornadas de Investigación en Psicología Universidad de Ciencias Empresariales y Sociales (UCES). Buenos Aires, octubre, 2008.

LIPOVETSKY, G. “La era del vacío” Editorial Anagrama. Barcelona, 1996.

REBÓN, Julián. "Transformaciones emergentes en el proceso de recuperación de empresas por sus trabajadores". Proyecto UBACyT N:42, Buenos Aires, 2008. Universidad de Buenos Aires. Disponible en revista digital del Observatorio Social de Empresas Recuperadas y Autogestionadas $\mathrm{N}^{\mathrm{o}} 1$ http://webiigg.sociales.uba.ar/empresasrecuperadas/Num_1/index.htm

Aires, 2004.

Desobedeciendo al desempleo. Ediciones PICASO, La rosa blindada. Buenos

"Empresas recuperadas y procesos emancipatorios" en Resistencias laborales. Experiencias de repolitización del trabajo en Argentina". Red insumisos latinoamericanos. Buenos Aires. 2009.

RUGGERI, A. "Las Empresas Recuperadas en la Argentina: Informe del Tercer Relevamiento de Empresas Recuperadas por sus trabajadores". Programa de Facultad Abierta, Secretaría de Investigación, Facultad de Filosofía y Letras. Ediciones de la Cooperativa Chilavert. Buenos Aires, 2010.

ULLOA, F. "La clínica psicoanalítica. Historial de una práctica” Paidós. Buenos Aires, 1995.

WYCZYKIER, G. "De la dependencia a la autogestión laboral". Prometeo libros. Buenos Aires, 2009.

Recebido em: 18/07/2013

Aprovado em: 01/08/2013 